\title{
Erratum to: Managing biological invasions: charting courses to desirable futures in the Cape Floristic Region
}

\author{
Núria Roura-Pascual • David M. Richardson • \\ R. Arthur Chapman · Tanja Hichert • \\ Rainer M. Krug
}

Published online: 1 September 2010

(C) Springer-Verlag 2010

\section{Erratum to: Reg Environ Change \\ DOI 10.1007/s10113-010-0133-5}

The original version of this article unfortunately contained a mistake. In Fig. 2, the title of the $x$-axis should be "Uncertainty", not "Uncertainy".

The online version of the original article can be found under doi:10.1007/s10113-010-0133-5.

N. Roura-Pascual · D. M. Richardson · R. M. Krug

Centre for Invasion Biology, Department of Botany \& Zoology,

Stellenbosch University, Private Bag X1, Matieland 7602,

South Africa

e-mail: rich@sun.ac.za

R. M. Krug

e-mail: Rainer@krugs.de

R. Arthur Chapman

CSIR Natural Resources and the Environment,

P.O. Box 320, Stellenbosch 7599, South Africa

e-mail: arthur@oneworldgroup.co.za

R. Arthur Chapman

OneWorld Sustainable Investments, PO Box 8359,

Roggebaai 8012, South Africa

T. Hichert

Institute for Futures Research, Stellenbosch University,

P.O. Box 2010, Bellville 7535, South Africa

e-mail: Tanja@hichert.co.za

N. Roura-Pascual ( $₫)$

Àrea de Biodiversitat, Centre Tecnològic Forestal de Catalunya, Ctra. de St. Llorenç de Morunys km 2, 25280 Solsona, Catalonia

e-mail: nrourapascual@gmail.com 